\title{
Citizen Preparedness for Disasters: Are Current Assumptions Valid?
}

Lori Uscher-Pines, PhD; Anita Chandra, DrPH; Joie Acosta, PhD; Arthur Kellermann, MD

\section{ABSTRACT}

US government programs and communications regarding citizen preparedness for disasters rest on several untested, and therefore unverified, assumptions. We explore the assumptions related to citizen preparedness promotion and argue that in spite of extensive messaging about the importance of citizen preparedness and countless household surveys purporting to track the preparedness activities of individuals and households, the role individual Americans are being asked to play is largely based on conventional wisdom. Recommendations for conceptualizing and measuring citizen preparedness are discussed.

(Disaster Med Public Health Preparedness. 2012;6:170-173)

Key Words: personal preparedness, community resilience

F ollowing the terrorist attacks of September 11,2001, and Hurricane Katrina in 2005, the US government and many nongovernmental organizations sought to boost citizen preparedness for disasters. For example, the 2004 report from the Federal Emergency Management Agency (FEMA), Are You Ready? describes our nation's emergency management system as a pyramid, with citizens forming the base. As a result of their critical role within a larger disaster response structure, individual citizens have a responsibility to take appropriate steps to protect themselves and their families, and to be self-reliant. ${ }^{1}$ In countless speeches and public remarks, high-level government officials have sought to reinforce these sentiments, arguing that "citizens provide the first line of disaster response" and "citizen preparedness is fundamental to national preparedness."

For much of the past decade, the major focus of citizen preparedness activities has been on urging individuals to plan on being self-sufficient for three days (and perhaps longer) following a disaster. This position is predicated on the fact that local first responders cannot attend to every victim's needs for rescue, food, shelter, and medical care, and external assistance may not arrive for multiple days. ${ }^{1,2}$ As a result, presumably "able" families that are not prepared to be self-sufficient during the immediate postevent period (when resources are often stretched to their limits) pull responders and critical resources away from neighbors with vulnerabilities who truly require assistance. ${ }^{3}$

In light of these realities, disaster preparedness experts broadly agree that citizen preparedness requires households to have an emergency plan, to stockpile supplies such as water and prescription medications, and to stay informed of community plans. ${ }^{4}$ This vision of citizen preparedness is extended to such common sense recommendations as "expect to be on your own for three days" and "store extra water in the basement." Some officials believe that fostering realistic expectations about how quickly help will arrive averts panic. It may also deflect criticism of government inaction. Some disaster response experts hypothesize that promoting preparedness by individuals reduces personal feelings of guilt and fosters faster physical and mental health recovery following a disaster.

Despite the value and seeming clarity of these messages, citizen uptake has been mixed. Four years after Hurricane Katrina caused widespread devastation, only $56 \%$ of respondents to the 2009 edition of FEMA's Citizen Corp Survey reported setting aside any supplies in their home for use in a disaster. Less than one-half (44\%) reported having a household emergency plan. ${ }^{5}$ Additional national surveys report dismal findings. ${ }^{6,7}$ According to a 2009 Red Cross survey, $20 \%$ of US citizens have taken no concrete steps to prepare. ${ }^{6}$ Furthermore, because all household surveys tend to be skewed in a positive direction by social desirability bias, the actual proportion of citizens who are prepared is probably less, perhaps much less.

Given the sustained public relations effort that has accompanied citizen preparedness campaigns, it is reasonable to ask, Why does advice regarding citizen preparedness fail to resonate with the American public? Few would disagree with the notion that citizen preparedness is critical for overall disaster preparedness; however, if the existing messages are not influencing behavior, perhaps it is time to rethink what we are doing. Are we failing to reach citizens the right way, failing to communicate the right message, or failing to measure preparedness activities in a valid manner?

We posit that the biggest problem with the existing approach to citizen preparedness is that the entire effort 
relies on largely untested, and therefore unverified, assumptions. Despite extensive messaging about the importance of citizen preparedness and countless household surveys purporting to track the preparedness activities of individuals and households, the role individual Americans are being asked to play is largely based on conventional wisdom. We argue that if the assumptions that underlie current efforts to boost citizen preparedness are faulty, they will not strengthen national preparedness; in fact, they could even undermine it.

Consider the following examples:

\section{ASSUMPTION 1: PREPARED, SELF-RELIANT CITIZENS ARE THE FOUNDATION OF A RESILIENT COMIMUNITY}

The newly released National Health Security Strategy from the US Department of Health and Human Services (HHS) has two overarching goals. One is to "foster community resilience." Communities comprise individuals as well as organizations; thus, the actions of individuals should be as relevant to the HHS vision of community resilience as citizen involvement is to FEMA's emergency management pyramid. However, while the literature on community resilience gives a passing nod to individual preparedness and self-reliance (eg, one definition makes a vague reference to community resilience as an "attitude"),, 9 few resilience experts have explicitly incorporated efforts to foster citizen preparedness into their conceptual models and frameworks. ${ }^{10,11}$ Thus, the proper role of citizen preparedness within a "resilient community" is unclear, even at the most basic conceptual level. As a result, the literature on community resilience and the concrete advice posted on www.ready.gov are not integrated in any obvious way.

Citizen preparedness is not only ignored in much of the academic work on resilience; it may not even be recognized as a valuable strategy when it is considered. For example, in 2008 a group of experts representing multiple disciplines was asked to rank a variety of activities in terms of their effectiveness for building community resilience. Mass marketing of individual readiness was ranked well below most preparedness activities. A sizable minority $(25 \%)$ of experts judged the activity to be "ineffective." ${ }^{2}$ The authors of this study asserted that there has been an overemphasis on citizen preparedness, when community rebound and recovery must rest on the connections between individuals. They also took issue with government initiatives that stress private citizens acting alone rather than in civic groups. ${ }^{12}$ In their view, stressing individual-level preparedness rather than concerted neighborhood action hinders community resilience rather than enhances it.

The tension here is that the community resilience literature views "social capital" (manifested in organized social networks such as faith communities and community partnerships) as hallmarks of a resilient community. In the view of these experts, urging individuals to look after themselves, and fielding surveys that promote stockpiling rather than maintenance of neighborhood linkages undervalues (and may even undermine) com- munity networks. From their perspective, prepared groups, rather than prepared individuals, should form the foundation of the emergency management pyramid.

\section{ASSUMPTION 2: WITH SO MANY DISASTERS, IT IS IRRATIONAL NOT TO PREPARE}

According to the Red Cross, slightly more than one-half of all Americans have experienced at least one significant emergency that forced them to evacuate their homes, to live without utilities for at least three days, or to provide first aid to others. ${ }^{6}$ In 2008 alone, there were 75 FEMA-declared major disasters in the United States. ${ }^{13}$ At the global level, during the past decade, natural disasters have affected over two billion people. ${ }^{14}$ Thus, one might consider it obvious that every individual should prepare and that those who do not are living in denial. This assumption ignores several rational reasons why an individual citizen may make a different choice. ${ }^{15}$ First, messaging about citizen preparedness does not consistently reach Americans. As a result, many are uninformed about the magnitude of risk and appropriate protective behaviors. A recent report that contrasted the culture of preparedness in the United States vs Israel noted that national campaigns in the United States predominantly rely on Web-based programming. The authors observed, "This approach not only favors those with access to Internet, but also places a required initiative on the public to seek the necessary information." ${ }^{4}$ In addition, a recent review of online preparedness materials revealed that the majority of Web sites with preparedness information were set at too high a reading level and were not suitable for diverse audiences. ${ }^{16}$ The limitations of this medium might explain why FEMA's Citizen Corp surveys found that public outreach and education campaigns did not significantly expand awareness from 2007 2009. ${ }^{5}$ Second, although disasters frequently occur, the risk to any single individual that they will be affected by a disaster in a particular year is quite small. Third, despite public warnings to the contrary, many citizens cling to the belief that they will receive swift assistance in an emergency. According to the 2009 Citizen Corp survey, 30\% of Americans are not prepared because they believe that emergency responders will help them. More than 60\% expect emergency responders will arrive within the first 72 hours following a major disaster. ${ }^{5}$ Finally, many lowincome individuals - those who typically bear the brunt of any disaster-simply lack the resources to meet government recommendations for preparedness. Research has shown that many low-income urban residents lack sufficient funds or even the storage space to maintain an adequately stocked disaster kit. ${ }^{17}$

\section{ASSUMPTION 3: PROMOTING INDIVIDUAL PREPAREDNESS IS CONSTRUCTIVE}

Emergency managers assume that encouraging citizens to prepare is constructive, because preparing requires little time and effort and has no obvious down side. However, even if the individual costs of citizen preparedness are modest for some Americans, encouraging citizens to devote resources to this activity may not be risk free. First, families whose daily lives are dominated by concerns about poverty, unemployment, and vio- 
lence may consider government exhortations to prepare for an earthquake or terrorist attack as misguided at best, and out of touch at worst. There are also hypothetical reasons to worry that fostering individual preparedness could engender a false sense of security and encourage some families to ignore official guidance to evacuate because they can "ride out" the disaster. Highly self-reliant individuals may be inclined to make their own decisions rather than deferring to the advice of authorities. ${ }^{15}$

The focus on stockpiling three days of supplies and understanding evacuation routes may produce another unintended consequence; it may inadvertently foster the expectation that preparedness is all about planning for a few days of hardship. In reality, preparedness should include planning for both the immediate response phase and a far longer period of recovery. Major events such as Hurricane Katrina and the Deepwater Horizon oil spill have shown that disasters can disrupt daily life for extended periods of time. While promoting self-sufficiency may be useful for the immediate phase of a response, it may impede the rapid community mobilization required for recovery. Also, because, ultimately, recovery determines how quickly a community will return to normalcy after a disaster, preparedness messages should address actions that extend beyond the period of immediate response.

\section{ASSUMPTION 4: CITIZEN PREPAREDNESS CAMPAIGNS ARE INFORMED BY EVIDENCE}

It would be reasonable to presume that a body of evidence (eg, from retrospective studies of previous disasters) informs the content of citizen preparedness campaigns, but this is not the case. According to one review of citizen preparedness guides, "Although federal and state planning documents speak to the importance of citizen engagement, this emphasis did not result from an evidence base. In addition, the literature does not quantify or provide an evidence base or best practices for citizen engagement in preparedness." 18 If no universal definition of individual preparedness exists, it follows that the specifics on what to do (ie, beyond stockpile generic supplies and develop a plan) to be prepared vary. ${ }^{7}$ When recommendations are made regarding the optimal content of a disaster kit, they are typically the product of an expert panel discussion, rather than empirical evidence. Even core tools for measuring citizen preparedness, such as the Public Readiness Index, were developed through focus groups and expert consensus rather than evidence. ${ }^{19}$ Before future tools are endorsed by governments and published for widespread use, we should be confident that they are valid.

\section{ASSUMPTION 5: SURVEYS OF BUYING AND PLANNING BEHAVIOR ARE USEFUL FOR GAUGING CITIZEN PREPAREDNESS}

Various organizations, including the federal government, collect survey data on citizen preparedness. Most track only planning and buying behaviors. Citizen Corp, for example, maintains a database of 134 household preparedness surveys. ${ }^{20}$ Numerous studies have aimed to identify predictors of pre- paredness (ie, individuals with higher incomes and better health are more likely to prepare). 5, $7,21,22$ Clearly, many organizations and authors believe that surveying the public is constructive. The assumption in seeking out "predictors" of certain behaviors seems to be that these activities are valuable and should be encouraged. It is unclear, however, how the results of these surveys are used, what they reveal, and how accurately they track progress over time. For example, how should a local public health official interpret a $5 \%$ change in the number of people who report they are trained to perform cardiopulmonary resuscitation or own a first-aid kit?

Typically, the measures included in these surveys are those that are the easiest to collect and have, on their face, a putative link to preparedness. But it is far from clear that the behaviors these surveys purport to measure are the most salient measures of citizen preparedness.

\section{CONCLUSION}

One assumption that we do not question is that the actions of individual citizens are critical to supporting disaster preparedness and response. Experts have noted that even in catastrophic terrorist attacks, individuals can take simple, concrete steps to save their own lives and the lives of those around them. ${ }^{23}$ Also, evidence from numerous disasters suggests that most vital rescue work, including the immediate provision of first aid, transportation of casualties to hospitals for treatment, and the provision of food and shelter, is done by friends and neighbors who are themselves victims of the disaster. ${ }^{15,24,25} \mathrm{Ac}$ cording to Craig Fugate, administrator of FEMA, "Neighbors are almost always the most effective and most immediate first responders." Statements like this suggest that efforts to promote citizen preparedness should extend beyond personal planning and buying behaviors to promote bystander involvement and community action in the face of shared threats.

Bystander engagement has the potential to save lives but it poses two potential problems. First, improvised responses can complicate the official response. Second, in certain situations our natural instinct to come to the aid of others can put our own survival at risk. ${ }^{23}$ Furthermore, although productive bystander responses are common, research suggests they are not inevitable $^{15}$; thus, disaster preparedness planners should support research on how best to encourage community engagement and effective bystander response as core components of citizen preparedness. For example, we need to understand how to cultivate a robust bystander response that supports rather than undermines the parallel activities of first responders. At a minimum, we need to rethink the current approach to citizen preparedness, which is doing little to affect widespread public apathy. We should explore whether the current goal of promoting individual self-sufficiency for three days is the best approach to citizen preparedness, especially because local recovery from disasters requires community mobilization and civic engagement as neighbors care for each other. 
Community resilience experts recognize that preparedness is only part of the battle; swift recovery requires more. The growing attention to community resilience in academic as well as policy circles provides a window of opportunity to critically examine the current approach to fostering citizen preparedness to ensure its continued relevance. Going forward, we need actual data to inform our recommendations for citizen preparedness, and meaningful, consistent measures to monitor citizen preparedness on an ongoing basis. For example, planners would benefit from case studies on what supplies and training help individuals and communities respond to actual events. We need empirical data about which aspects of bystander response are most helpful and which may be counterproductive. Evidence and measurement, combined with a critical examination of long-held assumptions, offer us the surest path to preparedness.

Author Affiliations: RAND Corporation, Arlington, Virginia (Drs UscherPines, Chandra, Acosta, and Kellermann).

Correspondence: Lori Uscher-Pines, PhD, 1200 S Hayes St, Arlington, VA 22202 (e-mail: luscherp@rand.org).

Received for publication October 10, 2010; accepted February 19, 2011.

\section{REFERENCES}

1. Federal Emergency Management Agency. Are You Ready? An In-depth Guide to Citizen Preparedness. 2004. http://www.citizencorps.gov/ready/. Accessed August 20, 2010.

2. Fugate C. Post Katrina: What It Takes to Cut the Bureaucracy and Assure a More Rapid Response. Washington DC: July 27, 2009. http://www.fema .gov/pdf/about/testimony/072709_fugate.pdf.

3. Leggiere P Big gaps remain in citizen preparation. HSToday. August 28, 2009.

4. McGee S, Bott C, Gupta V, Jones K, Karr A. Public Role and Engagement in Counterterrorism Efforts: Implications of Israeli Practices for the United States. Final Report. April 2, 2009. Arlington, Virginia: Deptof Homeland Security; 2009. http://www.homelandsecurity.org/docs/reports /Public_Role_in_CT_Israeli_Practices_Task_08-22.pdf.

5. FEMA Issues Report on Personal Preparedness in America. Washington, DC: Federal Emergency Management Agency; 2009.

6. American Red Cross. American Red Cross Emergency Preparedness Survey. 2009. http://www.readyrating.org/Businesses/ReasonstoPrepare .aspx. Accessed April 10, 2012.

7. Ablah E, Konda K, Kelley CL. Factors predicting individual emergency preparedness: a multi-state analysis of 2006 BRFSS data. Biosecur Bioterror. 2009;7(3):317-330.

8. US Department of Health and Human Services. National Health Security Strategy of the United States of America: 2009. Washington, DC: US Department of Health and Human Services; 2009.

9. Pfefferbaum B, Pfefferbaum R, Norris F. Community resilience and wellness for children exposed to Hurricane Katrina. In: Kilmer R, Gil-Rivas V, Tedeschi R, Calhoun L, eds. Helping Families and Communities Recover from Disaster: Lessons Learned from Hurricane Katrina and Its Aftermath. Washington, DC: American Psychological Association; 2009.
10. Chandra A, Acosta J, Meredith L, et al. Understanding Community Resilience in the Context of National Health Security. Arlington, Virginia: RAND Corp; 2010.

11. Norris FH, Stevens SP, Pfefferbaum B, Wyche KF, Pfefferbaum RL. Community resilience as a metaphor, theory, set of capacities, and strategy for disaster readiness. Am J Community Psychol. 2008;41(1-2):127-150.

12. Schoch-Spana M, Courtney B, Franco C, Norwood A, Nuzzo JB. Community resilience roundtable on the implementation of Homeland Security Presidential Directive 21 (HSPD-21). Biosecur Bioterror. 2008;6(3): 269-278.

13. Federal Emergency Management Agency. Declared Disasters by Year or State. 2010. http://www.fema.gov/news/disaster_totals_annual.fema. Accessed August 20, 2010.

14. International Federation of Red Cross and Red Crescent Societies. World Disasters Report. Geneva, Switzerland: International Federation of Red Cross and Red Crescent Societies; 2008.

15. Helsloot I, Ruitenberg A. Citizen response to disasters: a survey of literature and some practical implications. J Contingencies Crisis Manage. 2004; 12(3):98-111.

16. Friedman DB, Tanwar M, Richter JV. Evaluation of online disaster and emergency preparedness resources. Prehosp Disaster Med. 2008;23(5): 438-446.

17. Eisenman DP, Glik D, Maranon R, Gonzales L, Asch S. Developing a disaster preparedness campaign targeting low-income Latino immigrants: focus group results for project PREP. J Health Care Poor Underserved. 2009; 20(2):330-345.

18. Delestienne E. The Duquesne Emergency Preparedness Project: An Examination of Existing Citizen Preparedness Guides and an Exploration of Community Perceptions and Emergency Preparedness Needs [master's thesis]. Pittsburgh, Pennsylvania: University of Pittsburgh, School of Public Health; 2009.

19. The Council for Excellence in Government. Are We Ready? Introducing the Public Readiness Index: A Survey-Based Tool to Measure the Preparedness of Individuals, Families and Communities. December 14, 2006. http://www .citizencorps.gov/downloads/pdf/ready/pri_report.pdf. Accessed August 20, 2010.

20. Citizen Preparedness Survey Database. Citizen Corps Survey Database Description, Methodology, and Inventory Update 2010. http://www.citizencorps .gov/downloads/pdf/ready/SurveyDatabaseUpdate_Spring2010_narrative .pdf. Accessed August 20, 2010.

21. Murphy ST, Cody M, Frank LB, Glik D, Ang A. Predictors of emergency preparedness and compliance. Disaster Med Public Health Prep. July 8, 2009. Epub ahead of print.

22. Eisenman DP, Zhou Q, Ong M, Asch S, Glik D, Long A. Variations in disaster preparedness by mental health, perceived general health, and disability status. Disaster Med Public Health Prep. 2009;3(1):33-41.

23. Davis L, LaTourrette T, Mosher D, Davis L, Howell D. Individual Preparedness and Response to Chemical, Radiological, Nuclear, and Biological Terrorist Attacks. Santa Monica, California: RAND Corp; 2003.

24. Jacob B, Mawson AR, Payton M, Guignard JC. Disaster mythology and fact: Hurricane Katrina and social attachment. Public Health Rep. 2008; 123(5):555-566.

25. AufderHeide E. Common misconceptions about disasters: panic, the "disaster syndrome," and looting. In: O'Leary M, ed. The First 72 Hours: A Community Approach to Disaster Preparedness. Lincoln, Nebraska: iUniverse Publishing; 2004. 